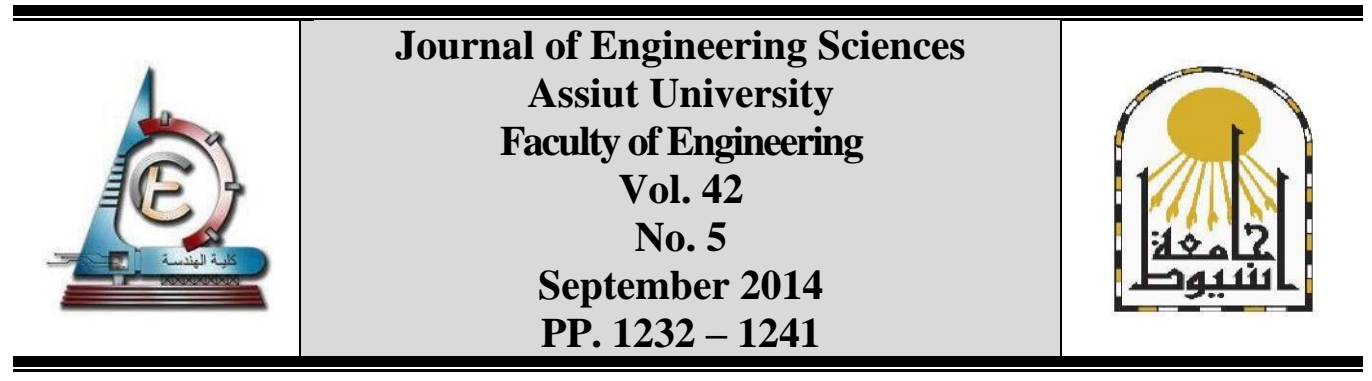

\title{
GRAIN REFINEMENT OF COMMERCIAL PURE ALUMINIUM BY ZIRCONIUM
}

\author{
A. E. Mahmoud ${ }^{1}$, M. G. Mahfouz ${ }^{2}$, H. G. Gad- Elrab ${ }^{3}$ and M. A. Doheim ${ }^{4}$ \\ ${ }^{1,3}$ Mining and Metallurgical Eng. Depart. Faculty of Engineering, Assiut University, Assiut, Egypt. \\ ${ }^{2,3}$ Nuclear Materials Authority- Egypt.
}

(Received 20 August 2014 Accepted 28 September 2014)

\begin{abstract}
The effect of $\mathrm{Zr}$ addition on the grain refinement of commercial pure aluminium (99.7\%) has been investigated in the present study. The results showed that addition of up to $0.3 \mathrm{wt}$. \% $\mathrm{Zr}$ significantly decreases the average grain size of aluminium from $1100 \mu \mathrm{m}$ to $162 \mu \mathrm{m}$ at holding time of 90 seconds. The refining effect of zirconium is attributed to the presence of $\mathrm{Al}_{3} \mathrm{Zr}$ particles in $\mathrm{Al}-\mathrm{Zr}$ master alloy. These particles are acting as effective heterogeneous nucleating sites for $\alpha$-Al.
\end{abstract}

Keywords: grain refinement - aluminum-zirconium-master alloy

\section{Introduction}

Aluminium is the most abundant element in the earth's crust. Pure aluminum possesses many advantages to be used extensively in industry, such as good electrical conductivity which superior to copper, better heat conductivity, lower density and higher plasticity [13].Metals and alloys usually solidify with coarse columnar grain structure under normal casting conditions [4]. So, the wide applications of aluminium in industry are limited because of the coarse microstructure which reduces the mechanical properties. It is of particular importance to improve the mechanical properties of aluminium by alloying or grain refining [5]. The process of grain refinement is carried out by addition of inoculants to aluminium to promote the formation of a fine and randomly oriented equiaxed grain structure upon solidification. Fine equiaxed grains impart high yield strength, high toughness, good extrudability, and uniform distribution of second phases and microporosity on a fine scale, improved machinability and cosmetic features [6-10]. The most common grain refiner used for aluminium and aluminium based alloys are the transition metals such as $\mathrm{Ti}, \mathrm{V}, \mathrm{Zr}$, etc. Transition metals are characterized by strong interatomic bonding, low diffusivity in solid aluminium and limited solubility ofthese metals in the solid solution [11]. The transition metals are used in the form of master alloys and can be used also as fluoride salts such as $\mathrm{K}_{2} \mathrm{TiF}_{6}$ and $\mathrm{K}_{2} \mathrm{ZrF}_{6}[12,13]$. However, use of such chemicals results in inconsistent performance and detrimental side-effects such as generation of toxic fluoride fumes, risk of

* Corresponding author.

E mail address: aelnakeep@yahoo.com 
halide inclusions and dross formation leading to high metal loss. The most common grain refiners used are Al-Ti, Al-Ti-C, and Al-Ti-B to melt before casting to promote refinement. Al-Ti-B is most widely used alloy with Ti: B ratios varying from 3:1 to 50:1. Titanium and boron are used to refine primary aluminum grains [14-16]. Addition of zirconium as a grain refiner introduces $\mathrm{Al}_{3} \mathrm{Zr}$ trialuminide particles, which are stable, coherent to the aluminium matrix and exhibit a small lattice parameter mismatch with the $\alpha$-Aland therefore act as efficient heterogeneous nucleants during solidification of aluminium [17-19]. With a $\mathrm{Zr}$ concentration of more than $0.1 \mathrm{wt}$. $\%, \mathrm{Al}_{3} \mathrm{Zr}$ particles heterogeneously nucleate the primary aluminium. When $\mathrm{Zr}$ addition level is less than $0.1 \mathrm{wt}$. \%, no effective grain refinement can be observed [20]. The aim of this work is to investigate the factors that influence the performance of zirconium as a grain refiner for commercial pure aluminium (99.7\%).

\section{Experimental procedures}

Commercial pure aluminium (99.7\%) was the starting material for all grain refinement experiments. $\mathrm{Al}-\mathrm{Zr}$ master alloy was used as the grain refiner. This master alloy was prepared by in-situ reduction of zirconium oxide $\left(\mathrm{ZrO}_{2}\right)$ with excess aluminum in the presence of cryolite flux. A commercially pure $\mathrm{Al}$ was melted in graphite crucible using electrical resistance furnace at $740{ }^{\circ} \mathrm{C}$. After addition of the grain refiner to molten aluminium, the melt was stirred with a graphite rod for $60 \mathrm{sec}$. to homogenize the melt. The molten aluminium was kept for a holding time ranging from 30 to $120 \mathrm{sec}$. then poured in a 75-mm diameter steel ring of $4 \mathrm{~mm}$ wall thickness and $25 \mathrm{~mm}$ height on a refractory brick. After solidifying and cooling, the specimens were prepared for macrograph by grinding and etching in solution contains $15 \mathrm{ml}$. $\mathrm{HF}, 15 \mathrm{ml} . \mathrm{HNO}_{3}, 45 \mathrm{ml}$. $\mathrm{HCl}$ and $25 \mathrm{ml}$. distilled water. For measuring the grain size of the grain refined specimens, specimens were ground and polished then the micrograph was revealed using Keller's reagent to reveal their grain boundaries. At least 40 pictures were taken for each sample, which were used in measuring the grain size with the linear intercept method.

\section{Results and discussions}

\subsection{Effect of holding time}

Fig. 1 shows the macrograph of the unrefined commercial pure aluminium (99.7\%). In the absence of grain refiner, it was noted that, aluminium exhibits fine columnar structure at the periphery and coarse equiaxed grains at the center of the specimen. The average grain size of unrefined aluminium is $1100 \mu \mathrm{m}$.

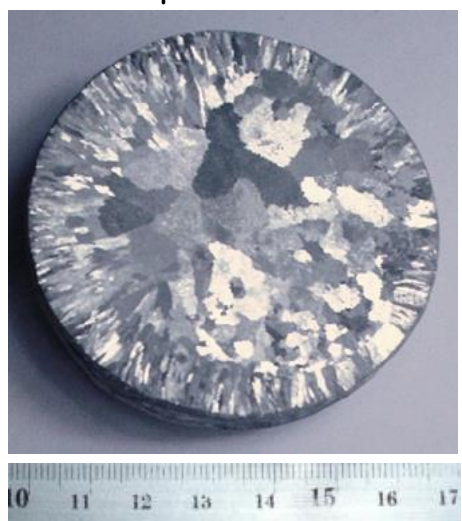

Fig. 1. Macrograph of unrefined aluminium specimen. 
Fig.2 (a-d) shows the macrographs of commercially pure Al grain refined with 0.2 wt. $\% \mathrm{Zr}$ addition level at different holding times (30, 60, 90, and 120 seconds). It is quite clear that the grain morphologies of all the specimens exhibit an equiaxed grain structure. There was a significant degradation in the grain refining performance of zirconium when molten aluminium was held at $740{ }^{\circ} \mathrm{C}$ for various holding times. Holding times longer than 90 seconds had an undesirable effect on the grain refining performance.

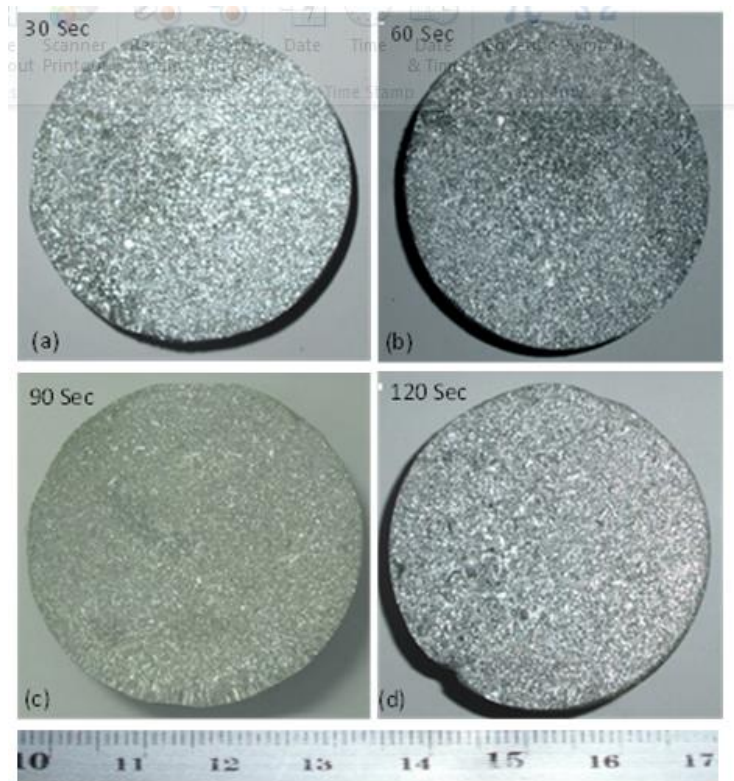

Fig. 2. Macrographs of commercially pure $\mathrm{Al}$ grain refined with 0.2 wt. $\% \mathrm{Zr}$ addition level at different holding time: (a) $30 \mathrm{sec}$., (b) $60 \mathrm{sec}$., (c) $90 \mathrm{sec}$, and (d) $120 \mathrm{sec}$.

Fig.3 (a-d) shows the effect of holding time on the microstructure of aluminium grain refined with $0.2 \% \mathrm{Zr}$. It can be noted that, the microstructure of the refined specimens demonstrates typical equiaxed grains and the efficiency of the grain refiner increases with increasing holding time till 90 seconds as shown in Fig.3 (c), then decreases. The fast action of zirconium in grain refinement of aluminium is an evident that the intermetallic phase $\mathrm{Al}_{3} \mathrm{Zr}$ is fine crystals which increase their dissolution rate [21].

Fig. (4) shows the average grain sizes of aluminium as a function of holding time at zirconium addition level of $0.2 \mathrm{wt}$. \%. It can be noted that the grain size progressively decreased with longer contact time till the grain size of aluminium reaches $186 \mu \mathrm{m}$ at holding time of 90 seconds, and then it increased to $220 \mu \mathrm{m}$ at holding time of 120 seconds. The refinement is attributed to the trialuminides crystals $\left(\mathrm{Al}_{3} \mathrm{Zr}\right)$ which gradually start to dissolve and lead to the reduction in their size and to the fragmentation of larger particles into smaller ones, providing more quantity of finer nuclei which would develop fine grain structure. If the melt is held for a long time after addition of zirconium as a grain refiner in the form of master alloy as in case of holding time of 120 seconds, the grain size of aluminium will increase. This means that the number of potent nucleating sites decreases. This is usually due to either dissolution or settling of $\mathrm{Al}_{3} \mathrm{Zr}$ during long holding. The time of dissolution should be a function of the temperature, size, morphology, number of particles, and the nature and concentration of alloying elements present in the melt. 

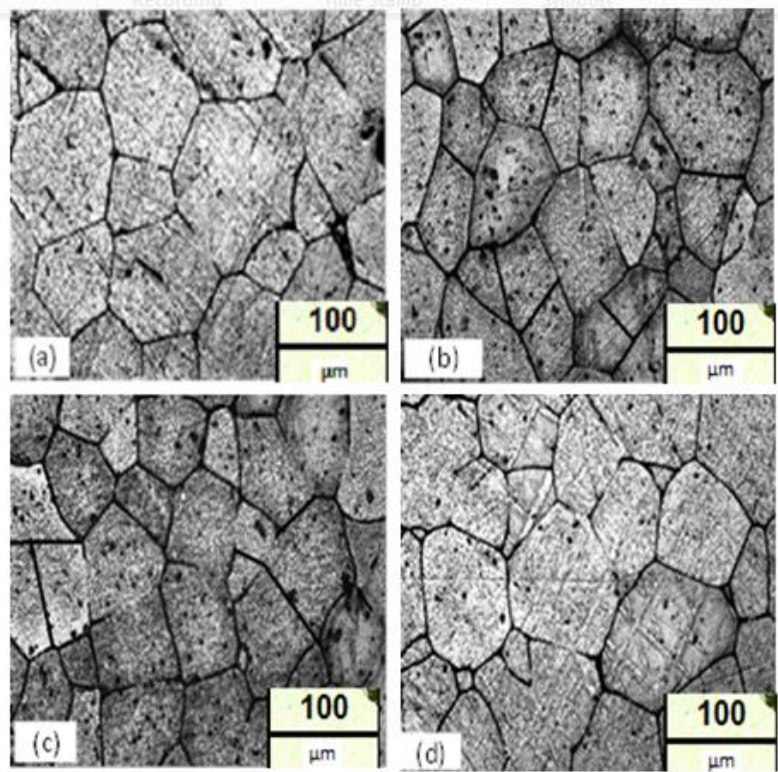

Fig. 3. Micrographs of grain refined aluminium by addition of $0.2 \mathrm{wt} . \% \mathrm{Zr}$ at various holding time: (a) $30 \mathrm{sec}$. , (b) $60 \mathrm{sec}$. , (c) $90 \mathrm{sec}$, and (d) $120 \mathrm{sec}$.

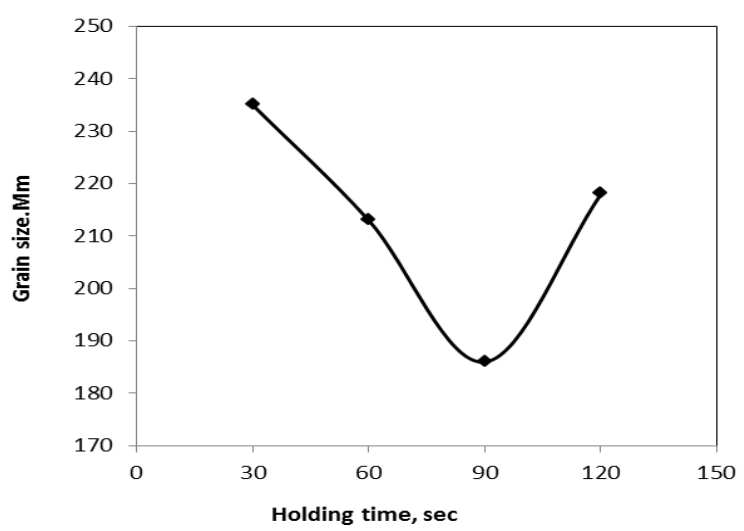

Fig. 4. Shows grain size of aluminium versus holding time at $\mathrm{Zr}$ addition level of 0.2 wt. \%.

In the present work, $0.2 \mathrm{wt} \% \mathrm{Zr}$ was added to find the optimum holding time. At $\mathrm{Zr}$ addition higher than $0.2 \mathrm{wt} \% \mathrm{Al}_{3} \mathrm{Zr}$ particles act as nuclei for solidification of $\mathrm{Al}$, hence $\mathrm{Zr}$ can operate as grain refiner of $\mathrm{Al}$. At $\mathrm{Zr}$ addition less than $0.1 \mathrm{wt} \%$ poor or no refining effect has been reported [20, 22].

\subsection{Effect of zirconium addition level}

From Fig.5 (a-f), it can be seen that the grain size of aluminium decreases greatly with increasing the addition of zirconium. All aluminium specimens are fine equiaxed grain structure but the finest equiaxed grains obtained at zirconium addition level of $0.3 \mathrm{wt} . \%$ as seen in Fig. (5e). This mainly due to increasing the nuclei seeds (nucleation rate), so that a large number of crystals are formed, which soon impinge on each other and prevent each other from further growth. 

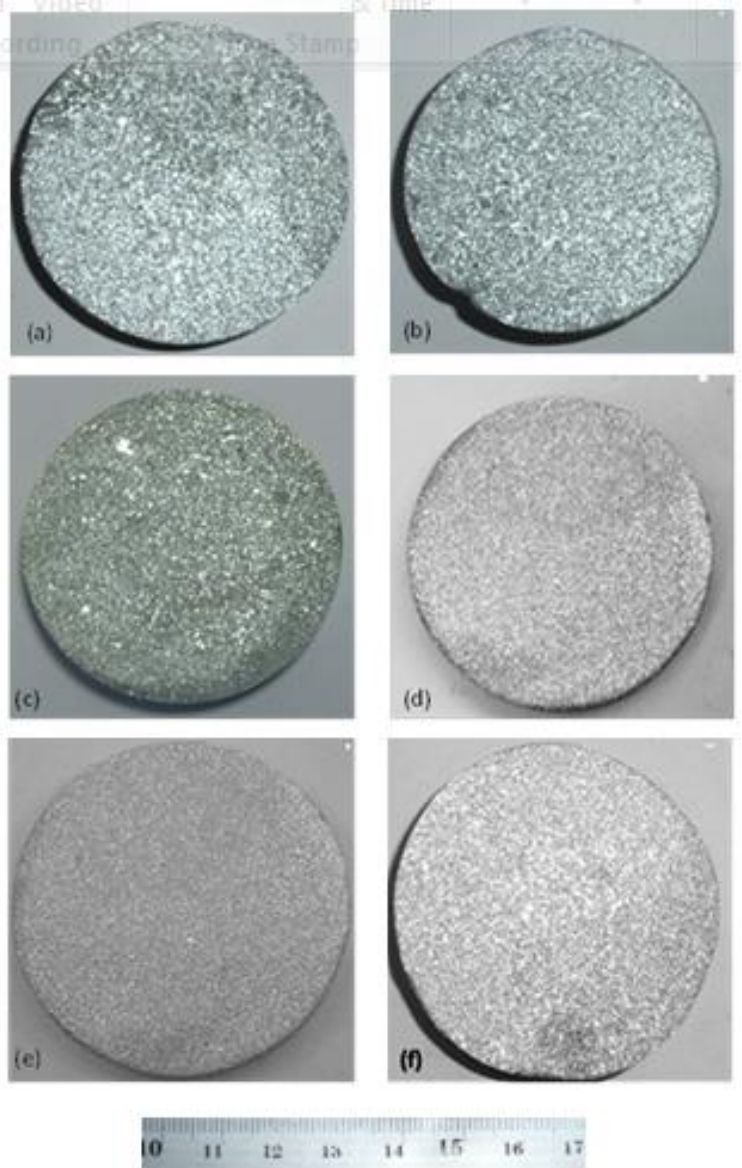

Fig. 5. Macrographs of commercially pure $\mathrm{Al}$ grain refined by different addition level of $\mathrm{Zr}$ and at holding time of 90 seconds: (a) 0.1, (b) 0.15, (c) 0.2, (d) 0.25, (e) 0.3 , and (f) $0.35 \mathrm{wt} . \%$

The additions of zirconium to aluminium melt in the form of aluminium-zirconium master alloy produce numerous potent and heterogeneous nuclei in the form of $\mathrm{Al}_{3} \mathrm{Zr}$. These metastable particles exhibit a small lattice parameter mismatch with the $\alpha$-Al solid solution and therefore act as efficient heterogeneous nucleants during solidification of $\alpha-\mathrm{Al}$ and refine the grain. Fig. 6 (a-f) shows that, the increase of $\mathrm{Zr}$ content from 0.1 to $0.3 \mathrm{wt}$. \% in the aluminium can result in a fine microstructure and almost significant reduction of the average grain size. However, by further addition of $\mathrm{Zr}(>0.3 \mathrm{wt}$. \%) to the aluminium, the average grain size almost slightly increased and the excess addition of $\mathrm{Zr}$ does not have a considerable effect on the microstructure of the aluminium.

Theoretically, the refinement mechanism of aluminum zirconium melts changes with variation of $\mathrm{Zr}$ content. When the $\mathrm{Zr}$ concentration is lower, $\mathrm{Zr}$ mainly interacts with atom cluster, forming steady atom clusters, then growing up and finally becoming nuclei. When the $\mathrm{Zr}$ concentration is higher, the formation of $\alpha-\mathrm{Al}$ is dependent on the peritectic reaction [19]: $\mathrm{L}+\mathrm{Al}_{3} \mathrm{Zr}=\alpha-\mathrm{Al}$ (solid solution). 

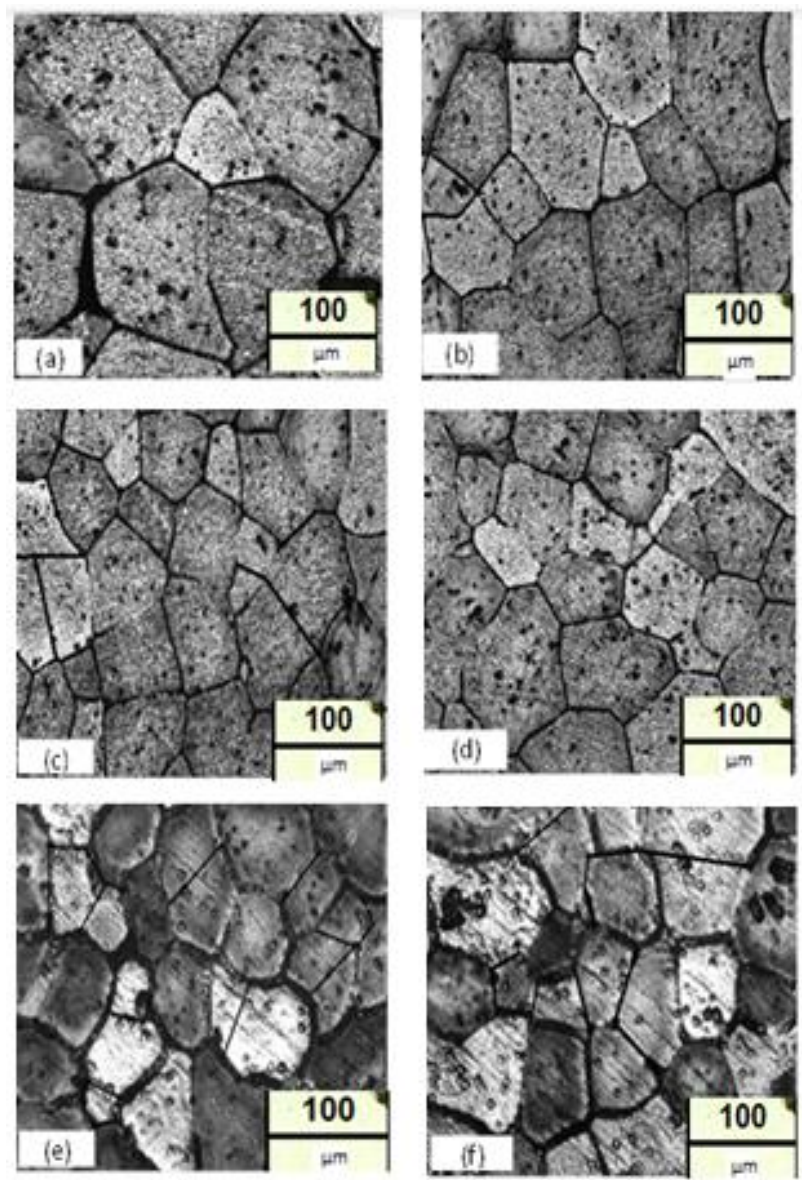

Fig. 6. Shows micrographs of commercially pure Al grain refined by different addition level of $\mathrm{Zr}$ and at holding time of 90 seconds: (a) 0.1, (b) 0.15, (c) 0.2, (d) 0.25 , (e) 0.3 , and (f) 0.35 wt.\%.

Fig. 7a Shows TEM image of Al grain refined with Zr. Fig. 7b shows a typical EDX spectrum of the particles observed at/or near the grain centers. $\mathrm{Al}_{3} \mathrm{Zr}$ particles which are very fine appear bright against the darker matrix. The variation of aluminium grain size due to increasing zirconium addition level is plotted in Fig.8. It can be noted that initial addition of $0.1 \% \mathrm{Zr}$ with holding time $90 \mathrm{sec}$. decreases the average grain size of aluminium from $1100 \mu \mathrm{m}$ to $240 \mu \mathrm{m}$. Further addition of zirconium $0.15,0.2,0.25$, and 0.3 wt. $\%$ at the same holding time ( $90 \mathrm{sec}$.) to aluminium results in finer grain sizes 212,186 , 172 , and $162 \mu \mathrm{m}$ respectively. At $\mathrm{Zr}$ addition level of $0.35 \mathrm{wt} \%$ the grain size of aluminium increased to $174 \mu \mathrm{m}$. 


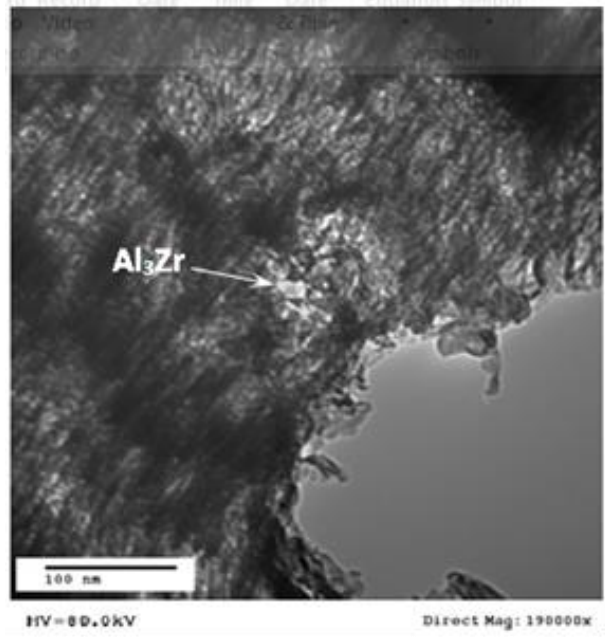

(a)

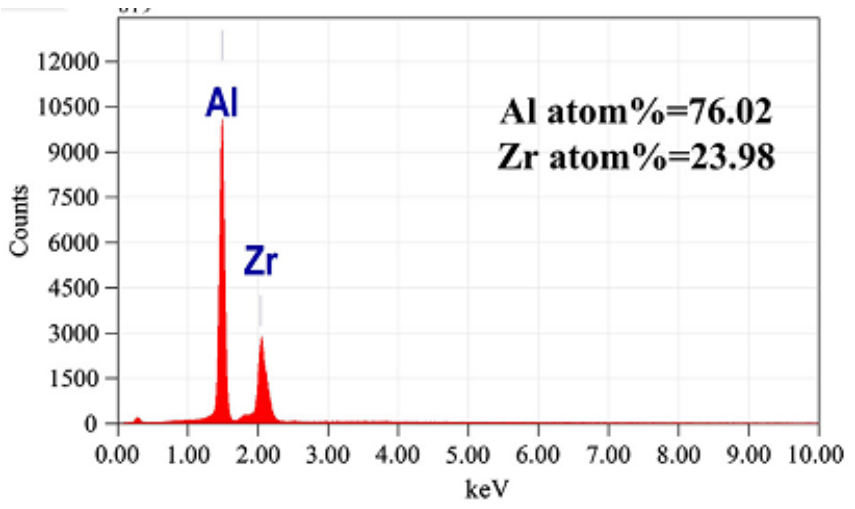

(b)

Fig. 7. (a) TEM image of Al grain refined with $\mathrm{Zr}$ (b) EDX spectrum taken from the particle at the grain centre.

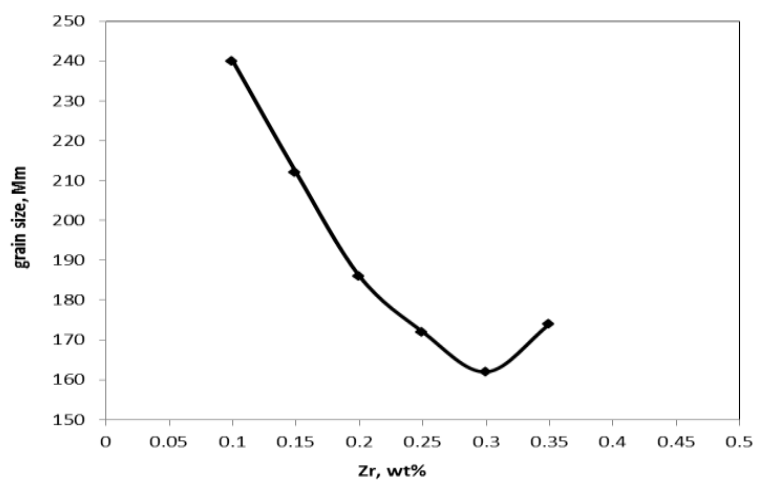

Fig. 8. Shows grain size of aluminium versus addition level of $\mathrm{Zr}$ at holding time of 90 seconds. 


\section{Conclusions}

The effect of zirconium on the grain refinement of commercial pure aluminium (99.7\%) is investigated by microstructure and macrostructure observation. The following conclusions can be made:

1- The optimum holding time of zirconium as a grain refiner in the melt of aluminium is 90 seconds.

2- The addition of $0.3 \%$ wt. $\% \mathrm{Zr}$ at holding time of 90 seconds, refine the grains of aluminium from $1100 \mu \mathrm{m}$ to $162 \mu \mathrm{m}$.

3- The efficiency of zirconium in grain refinement of aluminium is due to $\mathrm{Al}_{3} \mathrm{Zr}$, which heterogeneously nucleate the primary aluminium.

\section{REFERENCES}

[1] Z. Henghua, T.Xuan, S. Guangjie and X. Luoping "Refining mechanism of salts containing Ti and B elementsin purity aluminum" J. Mater. Process. Technol. 180 (2006) 60-65.

[2] X.D. Du"Study on ageing and creep of Al-0.1Zr alloy" Mater. Sci. Eng., A 432 (2006) 84-89.

[3] J.A. Omotoyinbo and I.O. Oladele"The Effect of plastic deformation and magnesium content on the mechanical properties of 6063 aluminium alloys" J. Miner. Mate. Charact. Eng. 9(2010)539-546.

[4] B. S. Murty, S. A. Kori, and M. Chakraborty "Grain refinement of aluminium and its alloys by heterogeneous nucleation and alloying"Int. Mater. Rev., 47, No 1 (2002) 4-28.

[5] P.K. Rajagopalan, I.G. Sharma , T.S. Krishnan"Production of Al-Zr master alloy starting from $\mathrm{ZrO}_{2} "$ J. Alloys Compd. 285 (1999) 212-215.

[6] Y. Zhang,N. Ma, H. Yi, S. Li and H. Wang"Effect of Fe on grain refinement of commercial purity aluminum"Mater. Des. 27 (2006) 794-798.

[7] P. S. Mohanty and J. E.Gruzleski "Mechanism of grain refinement in aluminium" Acta metall.mtater. 43, No. 5 (1995) 2001-2012.

[8] Y. Birol "Grain refining efficiency of Al-Ti-C alloys" J. Alloys Compd. 422 (2006) 128-131.

[9] M. Vandyoussefi and A.L. Greer "Application of cellular automaton-finite element model tothe grain refinement of directionally solidified Al-4.15 wt. \%Mg alloys" Acta Mater. 50 (2002) 1693-1705.

[10] N. R. Rathod J.V. Manghani "Effect of modifier and grain refinement on cast Al-7Si aluminium alloy: a review" Int. J. of Emerging Trends in Eng.Dev.5 (2012) 574-581.

[11] A. A. Mahasneh "Effect of vanadium addition at a rate of $0.1 \%$ on the mechanical characteristics, microstructure, and microhardness of $\mathrm{Al}-\mathrm{Cu}$ casted alloys"Mod.Appl. Sci.5, No. 2(2011) 92-102.

[12] J.M. Juneja "Preparation of aluminium-zirconium master alloys" Indian J. Eng. Mater. Sci. 9 (2002) 187-190.

[13] M. Johnsson"Grain refinement of aluminium studied by use of a thermal analytical technique"Thermochim. Acta, 256 (1995) 107-121.

[14]Z. Gao, H. Li,Y. Lai, Y.Ou and D. Li"Effects of minor Zr and Er on microstructure and mechanical propertiesof pure aluminum"Mater. Sci. Eng., A 580 (2013) 92-98.

[15]P. Moldovan andG. Popescu "The grain refinement of 6063 aluminum using Al-5Ti-1B and Al-3Ti-0.15C grain refiners"JOM 56, N0,11(2004)59-61.

[16] W. Ming-xing, P. Jin-hui, L.Zhi-yong, L.Zhong-xia, S.Tian-fu and Y. Sheng."Grain refining action of $\mathrm{Ti}$ existing in electrolytic low-titanium aluminum with Al-4B addition for superheated Al melt"Trans. Nonferrous Met. Soc. China 20(2010) 950-957.

[17]P. Cavaliere "Effect of friction stir processing on the fatigue properties of aZr-modified 2014 aluminium alloy"Mater. Charact. 57 (2006) 100-104. 
[18]C. Limmaneevichitr and W. Eidhed "Novel technique for grain refinement in aluminum casting by Al-Ti-B powder injection"Mater. Sci. Eng., A 355 (2003) 174-179.

[19] He Yongdong, Z.Xinming and C.Zhiqiang"Effect of Minor Cr, Mn, Zr, Ti and B on Grain Refinement of As-Cast Al-Zn-Mg-Cu Alloys" Rare Met.Mater. Eng. 39(7), (2010) 1135-1140.

[20] F. Wang,D.Qiu,Z. L. Liu,J. A. Taylor, M. A. Easton and M. X. Zhang "The grain refinement mechanism of cast aluminium by zirconium" Acta Mater.61 (2013) 5636-5645.

[21] A. A. Abdel-Hamid "Structure modification of the $\alpha^{\prime}$ phase in $\mathrm{Zn}-\mathrm{Al}$ cast alloys by microalloying" Z.Metallkd, 83 (1992) 314-318.

[22] S. Park, S. Han, S. K. Choi, H. M. Lee "Phase Equilibria of $\mathrm{Al}_{3}$ (Ti, V, Zr) intermetallic System" Scripta mater. 34, 11, (1996)1697-1704. 


\section{تدقيق الحبيبات للألمونيوم التجارى بواسطة الزركنيوم}

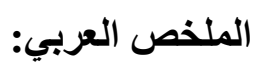

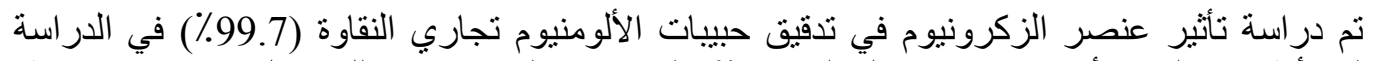

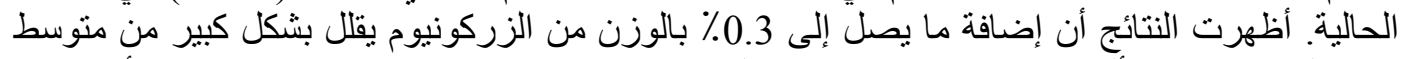

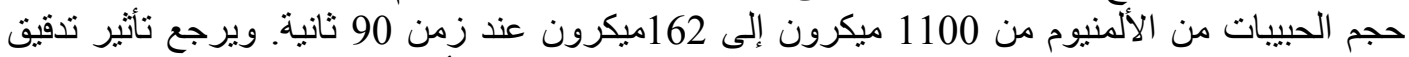

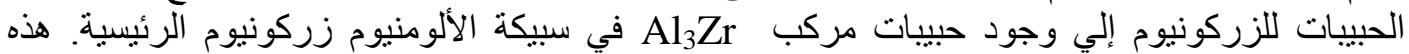

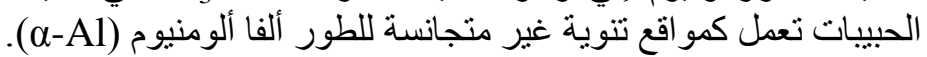

